\title{
The Turnover and Transport of Vitamin D and
}

\section{of a Polar Metabolite with the Properties of}

25-Hydroxycholecalciferol in Human Plasma

\author{
John Edgar Smith and DeWitt S. Goodman \\ From the Department of Medicine, Columbia University College of Physicians \\ and Surgeons, New York 10032
}

\begin{abstract}
A B S T RACT Four normal men were injected intravenously with physiological doses $(6 \mu \mathrm{g})$ of vitamin $\mathrm{D}_{8-}$ $1,2{ }^{3} \mathrm{H}$. Serial samples of plasma were collected for 50 days. Total lipid extracts were chromatographed on silicic acid columns or thin-layer plates in order to characterize the radioactive components. Labeled vitamin $D_{3}$ disappeared rapidly from plasma (initial half-life approximately $12 \mathrm{hr}$ ); after 7 days unchanged vitamin $D_{s}$ represented less than $1 \%$ of circulating radioactivity. Coincident with vitamin $\mathrm{D}_{3}$ disappearance a more polar labeled metabolite appeared with chromatographic and other properties identical with those of 25-hydroxycholecalciferol. The disappearance of the more polar metabolite was relatively slow with a half-life of $19.6 \pm 0.6$ days. A similar half-life was seen in a fifth subject, injected with $80 \mu \mathrm{g}$ of vitamin $\mathrm{D}_{3}{ }^{3} \mathrm{H}$. Most (approximately $92 \%$ ) of the plasma total radioactivity was represented by this component throughout the study. Plasma samples collected at various times were adjusted to density (d) 1.21 and were ultracentrifuged to separate plasma lipoproteins from proteins with $d>1.21$. In all samples, almost all (mean 94\%) of the radioactivity was found in association with proteins of $d>1.21$. This observation was confirmed by bioassay, measuring uptake of ${ }^{45} \mathrm{Ca}$ by intestinal slices. All plasma bioassayable vitamin D was found in association with proteins of $\mathrm{d}>1.21 ; 55 \%$ of bioactivity was found in the chromatographic fraction corresponding to 25-hydroxycholecalciferol and $44 \%$ in the fractions representing vitamin $D_{8}$. Since both vitamin $\mathrm{D}_{\mathbf{3}}$ and its 25-hydroxy metabolite are lipid-soluble sterol derivatives, the finding that these compounds do not cir-
\end{abstract}

Dr. Smith is a trainee under grant T1-AM-05397 from the National Institutes of Health, U. S. Public Health Service. Dr. Goodman is a Career Scientist of the Health Research Council of the City of New York under contract I-399.

Received for publication 11 March 1971 and in revised form 7 April 1971. culate in association with the known plasma lipoproteins provides presumptive evidence for the existence of a specific transport protein of $\mathrm{d}>1.21$. The transport protein for the polar metabolite has been partly characterized by gel filtration on Sephadex G-200 and by electrophoresis on polyacrylamide gel. The protein has an apparent size slightly smaller than plasma albumin (approximate mol wt 50,000-60,000) and an electrophoretic mobility very slightly greater than that of albumin. Studies are in progress to fractionate further and to characterize the transport protein.

\section{INTRODUCTION}

Recent studies of vitamin D metabolism have demonstrated that vitamin $\mathrm{D}$ is rapidly converted into a more polar metabolite after its intravenous injection into humans (1) or other animals (2-4). This metabolite, isolated from swine plasma, was identified as 25-hydroxycholecalciferol by Blunt, DeLuca, and Schnoes (3), and was shown to be biologically more active than cholecalciferol (vitamin $\mathrm{D}_{3}$ ) itself. The conversion of vitamin $\mathrm{D}_{3}$ to its 25-hydroxy "active" metabolite appears to occur in the liver (2) and may be an essential step in the activation of vitamin $\mathrm{D}$ for target tissues such as the intestinal muscosa (5) or bone (6). After its formation, 25-hydroxycholecalciferol is presumably transported from the liver to the target tissues where still more polar metabolites are formed and found (7-9) and where biological effects occur. It has also been suggested recently by Fraser and Kodicek (10) and confirmed by DeLuca (11) that the kidney is the site of conversion of 25-hydroxycholecalciferol to a still more polar active metabolite which is found in intestinal mucosa.*

* Note added in proof: This metabolite has very recently been identified as 1,25-dihydroxycholecalciferol [Lawson, D. E. M., D. R. Fraser, E. Kodicek, H. R. Morris, 
Limited information is available about the turnover and the plasma transport of vitamin $\mathrm{D}_{3}$ and of its 25-hydroxy metabolite. In 1967, Avioli, Lee, McDonald, Lund, and DeLuca reported that cholecalciferol- ${ }^{3} \mathrm{H}$ disappeared rapidly from the plasma of normal subjects with a halflife of $20-30 \mathrm{hr}$ (1). Coincident with the disappearance of cholecalciferol, a more polar metabolite with the properties of 25-hydroxycholecalciferol appeared. A slower plasma disappearance rate of vitamin $\mathrm{D}_{3}-{ }^{8} \mathrm{H}$ and a reduction in the amount of label appearing as the polar metabolite were observed in patients with vitamin D-resistant rickets (12). More recently, Mawer, Lumb, and Stanbury reported that, after the initial rapid disappearance of labeled vitamin $D_{\boldsymbol{z}}$ from human plasma, a prolonged second phase was seen with a half-life of $20-44$ days (13). A large proportion of the radioactivity found in plasma during the slow second phase was present as polar metabolites. In this study the amounts of labeled vitamin $\mathrm{D}$ injected were $10-20$ times the recommended daily allowance for vitamin D (14).

Before the isolation and identification of 25-hydroxycholecalciferol, several studies were conducted to examine the transport of vitamin D in human (15-17) and in rat $(18,19)$ serum. Human serum proteins were separated by agar-gel electrophoresis by de Crousaz, Blanc, and Antener, who found vitamin D activity, by bioassay, in the albumin and $\alpha_{2}$-globulin fractions (16). Thomas et al. also found vitamin $D$ activity in association with the $\alpha$-globulin and albumin fractions of human serum (15). Using labeled vitamin $\mathrm{D}_{3}$, Rikkers and DeLuca found that both the vitamin and its polar metabolite were associated with several protein bands, but particularly with an $\alpha$-globulin, after disc gel electrophoresis (19). No information is available about the plasma transport of 25-hydroxycholecalciferol in man.

We now report a study of the turnover of vitamin $\mathrm{D}_{\boldsymbol{3}}$ and of its polar metabolite in humans after the administration of small, physiological doses of the labeled vitamin. The transport of the vitamin and particularly of its polar metabolite has been examined in some detail. Neither the vitamin nor its polar metabolite circulates in association with the known plasma lipoproteins. The transport protein for the polar metabolite has been partly characterized with regard to apparent molecular size and to electrophoretic mobility.

\section{METHODS}

Experimental design. Five normal male volunteers, 24 $28 \mathrm{yr}$ of age, participated in this study. All subjects ate their

and D. H. Williams. 1971. Nature (London). 230: 228; Holick, M. F., H. K. Schnoes, H. F. DeLuca, T. Suda, and R. J. Cousins. 1971. Biochemistry. 10: 2799; Norman, A. W., J. F. Myrtle, R. J. Midgett, H. G. Nowicki, V. Williams, and G. Popják. 1971. Science (Washington). 173: $51]$.
TABLE I

Elution Scheme Employed for Silicic Acid Column Chromatography

\begin{tabular}{|c|c|c|c|}
\hline \multirow{2}{*}{$\begin{array}{c}\text { Fraction } \\
\text { No. }\end{array}$} & \multicolumn{2}{|r|}{ Eluted with: } & \multirow{2}{*}{$\begin{array}{c}\text { Distribution } \\
\text { of } \\
\text { recovered } \\
{ }^{3} \mathrm{H} \ddagger\end{array}$} \\
\hline & ml & Solvent* & \\
\hline & & & $\%$ \\
\hline 1 & 100 & $21 \%$ benzene in hexane & 1 \\
\hline 2 & 25 & $85 \%$ benzene in hexane & $<1$ \\
\hline 3 & 25 & $85 \%$ benzene in hexane & 7 \\
\hline 4 & 25 & $85 \%$ benzene in hexane & 20 \\
\hline 5 & 25 & $85 \%$ benzene in hexane & 2 \\
\hline 6 & 50 & $85 \%$ benzene in hexane & $<1$ \\
\hline 7 & 50 & Chloroform & $<1$ \\
\hline 8 & 50 & $10 \%$ methanol in chloroform & 66 \\
\hline 9 & 50 & $10 \%$ methanol in chloroform & 1 \\
\hline 10 & 50 & $60 \%$ methanol in chloroform & 2 \\
\hline 11 & 25 & Methanol & $<1$ \\
\hline
\end{tabular}

* $21 \%$ benzene in hexane means benzene-hexane, $21: 79(\mathrm{v} / \mathrm{v}) ; 10 \%$ methanol in chloroform means methanol-chloroform, 1:9; etc.

‡ Plasma sample obtained from subject F.B. $24 \mathrm{hr}$ after the intravenous administration of $6 \mu \mathrm{g}$ cholecalciferol-1,2-8 $\mathrm{H}$.

usual diets throughout the studies; none of them received, or had been taking, vitamin supplements. Each subject was given an intravenous injection of ${ }^{\mathrm{a}} \mathrm{H}$-labeled cholecalciferol. Serial samples of blood were collected, after $1,1,2,4,7$, 10 , and 15 days, and then at weekly intervals for a total of 7-8 wk, in syringes moistened with a solution of heparin. Relatively large samples, of approximately 100 and $500 \mathrm{ml}$, were collected on the 2 nd and 7 th days, respectively, for attempted fractionation of the transport protein. Blood cells were sedimented by centrifugation at $2000 \mathrm{rpm}$ for $30 \mathrm{~min}$ at $4^{\circ} \mathrm{C}$. Portions of the plasma samples were then either extracted with $\mathrm{CHCl}_{3}-\mathrm{CH}_{3} \mathrm{OH}$ (see below), subjected to ultracentrifugation in order to separate lipoproteins from other plasma proteins (see below), or stored in the frozen state at $-20^{\circ} \mathrm{C}$ for later study.

In the first, preliminary experiment, subject $\mathrm{C}$. $\mathrm{H}$. was given $80 \mu \mathrm{g}(7.36 \mu \mathrm{Ci})$ of cholecalciferol-1,2- ${ }^{8} \mathrm{H}_{2}$ (specific radioactivity $35.4 \mathrm{mCi} / \mathrm{mmole})^{1}$ dissolved in $0.7 \mathrm{ml}$ absolute ethanol in a manner similar to that of Avioli and coworkers $(1,12)$. The radioactive purity of the injected material exceeded $90 \%$ as assessed by thin-layer chromatography (TLC)..$^{2}$

In the second and major study, each of four subjects received $6 \mu \mathrm{g}(2.36 \mu \mathrm{Ci})$ of a high specific radioactivity (154 $\mathrm{mCi} / \mathrm{mmole}$ ) preparation of cholecalciferol-1,2- ${ }^{8} \mathrm{H}_{2}{ }^{1}$ dispersed in an isotonic $\mathrm{NaCl}$ solution. The cholecalciferol- ${ }^{8} \mathrm{H}$ was purified by TLC on silica gel, using benzene-ethyl acetate, $3: 1(\mathrm{v} / \mathrm{v})$ as solvent just before use. The purified cholecalciferol- ${ }^{3} \mathrm{H}$ was dissolved in $1 \mathrm{ml}$ of ethanol, and under sterile conditions was dispersed through a No. 26 hypodermic needle into $20 \mathrm{ml}$ of sterile $0.9 \% \mathrm{NaCl}$ solution. Each subject was injected with $4.5 \mathrm{ml}$ of the final dispersion.

Extraction and chromatography. Samples of whole plasma or of plasma fractions were extracted with 20 volumes of $\mathrm{CHCl}_{3}-\mathrm{CH}_{3} \mathrm{OH}, 2: 1$ (v/v) containing $1 \mathrm{mg}$ of butylated hydroxytoluene (BHT) per $100 \mathrm{ml}$ as an antioxidant. 1

${ }^{1}$ New England Nuclear Corp., Boston, Mass.

${ }^{2}$ Abbreviations used in this paper: BHT, butylated hydroxytoluene; RBP, retinol-binding protein; TLC, thin-layer chromatography; TMS, trimethylsilyl. 
mg of unlabeled carrier cholecalciferol ${ }^{3}$ was added to each extraction. Each extraction mixture was split into two phases by addition of 5 volumes of $0.05 \% \mathrm{H}_{2} \mathrm{SO}_{4}$, and the entire $\mathrm{CHCl}_{3}$ phase was collected and evaporated to dryness under a stream of nitrogen. Portions of the total lipid extracts so obtained were assayed directly for radioactivity; other portions were subjected to column or thin-layer chromatography.

Column chromatography was performed with amber glass columns of $1 \mathrm{~cm}$ diameter containing $5 \mathrm{~g}$ of silicic acid (Unisil, 100-200 mesh). ${ }^{4} 11$ fractions were eluted from each column in a stepwise procedure as shown in Table I. This elution scheme is a modification of the elution schemes employed in this laboratory for the separation of plasma neutral lipids and phospholipids $(20,21)$. The scheme shown in Table I was designed to achieve a clear separation of mono-hydroxy sterols (e.g. cholecalciferol) and di-hydroxy sterols (e.g. 25-hydroxycholecalciferol) from each other and from still more polar lipids. Experiments with pure reference compounds demonstrated that, in this scheme, cholecalciferol is eluted in fractions 3,4 , and 5, and 25hydroxycholecalciferol in fraction 8. During this study the mean ( \pm SEM) recovery of radioactivity applied to the columns was $102 \pm 2 \%$ for 47 chromatographic runs.

Portions of the total lipid extracts of the proteins with density (d) greater than 1.21 were chromatographed on silica gel thin-layer plates ${ }^{5}$ with benzene-ethyl acetate, $3: 1$, in an atmosphere of nitrogen and in the dark. Carrier 25hydroxycholecalciferol ${ }^{6}$ was added to some but not all samples before TLC. After chromatography the plates were lightly sprayed with a solution of Rhodamine $6 \mathrm{G}$, and the separated cholecalciferol $\left(R_{\boldsymbol{F}} 0.55-0.6\right)$ and 25-hydroxycholecalciferol $\left(R_{\boldsymbol{F}} 0.30\right)$ bands were visualized under ultraviolet light, scraped, and eluted with chloroform. The remainder of the plate was divided into bands of approximately $1 \mathrm{~cm}$ width, which were each scraped and eluted. The eluates were evaporated and assayed for radioactivity.

Trimethylsilyl(TMS) ether derivatives. TMS ether derivatives of the total lipid extracts of the proteins of $d>$ 1.21 were prepared from the plasma samples collected from subjects A. B. and F. B. 36 days after the injection of cholecalciferol- ${ }^{8} \mathrm{H}$. $1 \mathrm{mg}$ of carrier 25 -hydroxycholecalciferol was added to the extraction mixture for each of these samples. The total, lipid extract was suspended in $200 \mu 1$ of a solution of pyridine-hexamethyldisilazane-trimethylchlorosilane, 9:3:1 (22) (Sil-prep) ${ }^{7}$ and allowed to react for $60 \mathrm{~min}$. Portions of the reaction mixtures were then subjected to TLC on silica gel plates in two different systems: ( $a$ ) benzene-ethyl acetate, $3: 1$, and (b) two-directionally with benzene-hexane, $1: 1$, followed at right angles by methyl ethyl ketone-acetonitrile, $7: 3,80 \%$ saturated with mineral oil. The area of the carrier was located as described above, and the scraped bands or spots were eluted with hot benzene-ethyl ether, $1: 1$.

Separation of lipoproteins. Plasma lipoproteins were separated from proteins with hydrated density greater than 1.21 by ultracentrifugation, using a simplified modification of the method of Havel, Eder, and Bragdon (23). For each separation, $10 \mathrm{ml}$ of fresh plasma was placed in a $5 \times 3$ in. polyallomer tube containing $3.328 \mathrm{~g}$ of $\mathrm{KBr}$. After the $\mathrm{KBr}$

${ }^{3}$ Schwarz Bio Research Inc., Orangeburg, N. Y.

- Clarkson Chemical Co., Inc., Williamsport, Pa.

${ }^{5}$ Brinkmann Instruments Inc., Westbury, N. Y.

- A generous gift of the Upjohn Co., Kalamazoo, Mich., courtesy of Dr. John C. Babcock.

${ }^{7}$ Applied Science Laboratories Inc., State College, Pa. had dissolved, the tubes were filled with a $\mathrm{d} 1.21$ solution of $\mathrm{KBr}-\mathrm{NaCl}$ and centrifuged in a No. 40 rotor of a Spinco model L ultracentrifuge at $40,000 \mathrm{rpm}$ for $36-48 \mathrm{hr}$. The tubes were sliced in the clear zone, and the floating (lipoprotein, $d<1.21)$ and sedimenting $(d>1.21)$ fractions were collected separately.

Gel filtration and electrophoresis. Gel filtration was carried out on columns of Sephadex G- $200^{8}$ in a cold room at $4^{\circ}-5^{\circ} \mathrm{C}$. The columns were eluted with $0.02 \mathrm{M}$ phosphate buffer, $\mathrm{pH} 7.3$, containing $0.2 \mathrm{M} \mathrm{NaCl}$. The size of the column varied in different experiments, but the volume of the sample applied was restricted to $3 \%$ or less of the column bed volume. The samples subjected to gel filtration included the following: (a) a large sample of pooled plasma obtained from subjects A. B., F. B., R. H., and T. L. on the 7th day after the injection of cholecalciferol- ${ }^{8} \mathrm{H} ;(b)$ plasma obtained from subject $C$. $H$. on the 15 th day after injection; and $(c)$ a pooled sample of plasma obtained from subject $C$. $H$. on the 5 th, 27 th, and 34 th days of study.

Preparative polyacrylamide gel electrophoresis was performed with a Buchler " "poly-prep 200" apparatus as described previously (24).

Bioassay. The vitamin $\mathrm{D}$ activity of plasma and plasma fractions was estimated by the in vitro uptake of ${ }^{45} \mathrm{Ca}$ by intestinal slices $(25,26)$. The samples which were assayed included total lipid extracts of whole plasma and of the lipoprotein $(\mathrm{d}<1.21)$ and $\mathrm{d}>1.21$ fractions of plasma. The cholecalciferol-containing and 25-hydroxycholecalciferolcontaining fractions (fractions $3+4+5$ and fraction 8 , respectively) after silicic acid column chromatography of extracts of whole plasma were also bioassayed. Carrier vitamin $\mathrm{D}$ was not added at any time to these samples, and all organic solvents contained $1 \mathrm{mg}$ BHT per $100 \mathrm{ml}$. The $\mathrm{CHCl}_{3}$ extracts or column fractions derived from $20 \mathrm{ml}$ of plasma were concentrated under nitrogen to approximately $5 \mathrm{ml}$ and transferred to a vial containing $1 \mathrm{~g}$ of olive oil with $0.1 \%$ BHT $(w / w)$. The samples were flushed with nitrogen until the solvent was fully evaporated. The olive oil solutions and dilutions of USP reference vitamin $D_{3}$ were administered with calibrated dropping pipets to vitamin $\mathrm{D}$-deficient rats. The rats were prepared by feeding rachitogenic diet No. $2^{10}$ for 5 wk to weanling male rats of the Sherman strain ${ }^{11}$ kept in covered cages. Each rat received two drops initially and three drops $12 \mathrm{hr}$ later. The in vitro uptake studies were conducted $44-50 \mathrm{hr}$ after giving the initial dose. The intestines were removed and incubated as described by Gordan and Schachter (26) except that ${ }^{45} \mathrm{Ca}^{1}$ was used instead of ${ }^{47} \mathrm{Ca}$. The incubated intestinal slices (approximately $200 \mathrm{mg}$ ) were removed from the incubation medium, blotted dry, and homogenized with $2 \mathrm{ml}$ of $1 \mathrm{M}$ EDTA in a Potter-Elvehjem homogenizer. The homogenates were centrifuged at $12,000 \mathrm{~g}$ for $30 \mathrm{~min}$, and $0.2 \mathrm{ml}$ of the supernatant solutions each was suspended in $1 \mathrm{ml}$ of 1 M hyamine hydroxide in methanol. After the suspensions became clear, $10 \mathrm{ml}$ of the counting solution described by Bray (27) was added, and the vials were shaken intermittently until a gel formed. After standing overnight at room temperature, the samples were assayed for ${ }^{45} \mathrm{Ca}$ in a Packard Tri-Carb liquid scintillation counter.

Other procedures. Radioassay for ${ }^{8} \mathrm{H}$ was carried out by dissolving samples in $15 \mathrm{ml}$ of $0.5 \%$ diphenyloxazole in toluene followed by assay with a Packard liquid scintillation

${ }^{8}$ Pharmacia Fine Chemicals Inc., Piscataway, N. J.

${ }^{\circ}$ Buchler Instruments, Inc., Fort Lee, N. J.

${ }^{10}$ Nutritional Biochemicals Corporation, Cleveland, Ohio.

${ }^{11}$ Camm Research Institute, Inc., Wayne, N. J. 


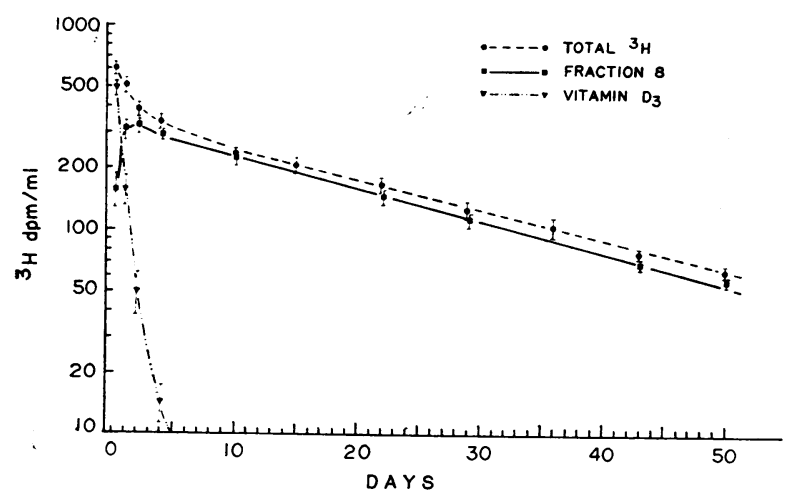

FIGURE 1 The turnover of plasma vitamin $D$ after the injection of $6 \mu \mathrm{g}$ of cholecalciferol- ${ }^{8} \mathrm{H}$ into each of four subjects. The points show the mean ISEM values (in brackets) for plasma total radioactivity, and for plasma- ${ }^{3} \mathrm{H}$ recovered in the cholecalciferol-containing fractions (labeled: vitamin $\mathrm{D}_{3}$ ) and in the 25-hydroxycholecalciferolcontaining fraction (labeled: fraction 8) after silicic acid column chromatography.

counter. Quenching was corrected for, where appropriate, by means of an automatic external standardization system.

Saponification of the total lipid extract of a $d>1.21$ sample was conducted in $2.15 \mathrm{ml}$ of $2.2 \% \mathrm{KOH}$ in $63 \%$ ethanol at $65^{\circ}-70^{\circ} \mathrm{C}$ under nitrogen for $2 \mathrm{hr} .1 \mathrm{ml}$ of water was added, and the nonsaponifiable lipids were collected by three extractions, each time with $5 \mathrm{ml}$ of hexane.

The half-life of the slow, semilogarithmic disappearance of radioactivity from plasma (see Results) was determined for each subject on the eight observations made between the 4th and 50th days after the injection of cholecalciferel${ }^{2} \mathrm{H}$. For subject C. $\mathrm{H}$. nine observations between the 7 th and 56th days were used. Linear regression lines of the logarithm of the concentration of radioactivity vs. time in days were calculated by the method of least squares (28), using a Wang ${ }^{12}$ model 700 electronic calculator. The halflives were calculated from the regression lines.

\section{RESULTS}

Turnover of radioactive vitamin $D_{s .}$ Fig. 1 shows the results obtained with the four subjects who were injected with $6 \mu \mathrm{g}$ of cholecalciferol- ${ }^{-} \mathrm{H}$. The semilogarithmic plot of the concentration of plasma total radioactivity vs. time described a curve during the first 4 days, whereas beyond this time the plot followed a straight line.

Extracts of each of the plasma samples collected in this study were analyzed by silicic acid column chromatography. In all samples, quantitatively significant amounts of ${ }^{3} \mathrm{H}$ were only recovered in the cholecalciferolcontaining fractions (fraction $3+4+5$ ) and in the 25-hydroxycholecalciferol-containing fraction (fraction 8). A small amount of ${ }^{8} \mathrm{H}$ was also consistently recovered in fraction 10, which contained a mean ( $2.4 \pm 0.3 \%$ of the recovered ${ }^{3} \mathrm{H}$ for the samples analyzed. (See Table I for a representative example.) No informa-

\footnotetext{
${ }^{12}$ Wang Laboratories, Tewksbury, Mass.
}

tion is available about the labeled compounds which were recovered in fraction 10.

During the early, curvilinear part of the plasma total radioactivity plot, labeled cholecalciferol disappeared rapidly from plasma, with an initial half-life, during the first $48 \mathrm{hr}$, of $12 \mathrm{hr}$ (Fig. 1). Cholecalciferol represented only $13 \%$ of the total plasma radioactivity after $48 \mathrm{hr}$ and less than $1 \%$ after 7 days in the four subjects receiving the $6 \mu \mathrm{g}$ dose. In subject $\mathrm{C}$. $\mathrm{H}$., who received the $80 \mu \mathrm{g}$ dose, cholecalciferol- ${ }^{\mathrm{B}} \mathrm{H}$ disappearance was less rapid with an initial half-life of $34 \mathrm{hr}$. In this subject, cholecalciferol represented $49 \%$ of the total plasma radioactivity after $48 \mathrm{hr}$ and $3 \%$ after 12 days.

Coincident with cholecalciferol- ${ }^{3} \mathrm{H}$ disappearance a more polar labeled component appeared with the chromatographic properties of 25-hydroxycholecalciferol (eluted in silicic acid column fraction 8, and see below). This component represented approximately $92 \%$ of the plasma total radioactivity throughout the linear portion of the semilogarithmic turnover plot. The disappearance of this polar metabolite was relatively slow with a halflife of $19.6 \pm 0.6$ days (Table II). The semilogarithmic disappearance rate of plasma total radioactivity was identical with that of the polar metabolite (Fig. 1 and Table II). As shown in Table II, the turnover rate of the polar metabolite was similar in the subject (C. H.) who received the $80 \mu \mathrm{g}$ dose to the rate observed in the subjects given $6 \mu \mathrm{g}$.

Characterization of the polar metabolite. The labeled metabolite eluted in fraction 8 from silicic acid columns exhibited chromatographic and other properties of 25hydroxycholecalciferol. The methods used to compare the properties of the labeled polar metabolite with those of authentic 25-hydroxycholecalciferol (in addition to silicic acid column chromatography) included TLC, formation of the TMS ether derivative and TLC in two different systems, and saponification and chromatography of the nonsaponifiable lipids.

TABLE II

Turnover of Plasma Total Radioactivity and of the Labeled Polar Metabolite of Vitamin $D_{3}$

\begin{tabular}{|c|c|c|}
\hline Subject & $\begin{array}{l}\text { th of total } \\
\text { plasma-2 }\end{array}$ & $\begin{array}{c}\text { th of polar } \\
\text { metabolite--2 } \mathrm{H}^{*}\end{array}$ \\
\hline & days & days \\
\hline A. B. & 18.1 & 18.1 \\
\hline F. B. & 17.2 & 18.0 \\
\hline R. H. & 20.4 & 20.1 \\
\hline T. L. & 21.4 & 20.6 \\
\hline C. $\mathrm{H}$. & 20.7 & 21.1 \\
\hline Mean 土SEM & $19.6 \pm 0.8$ & $19.6 \pm 0.6$ \\
\hline
\end{tabular}

* Metabolite with the properties of 25-hydroxycholecalciferol (see text). 
On TLC in benzene-ethyl acetate, $3: 1$, the radioactivity in column fraction 8 was found to comigrate with authentic 25-hydroxycholecalciferol. In a representative experiment, a pooled extract of plasma proteins of $d>$ 1.21 obtained $48 \mathrm{hr}$ after injection was analyzed by TLC. $11 \%$ of the ${ }^{3} \mathrm{H}$ cochromatographed with carrier cholecalciferol and $83 \%$ with carrier 25-hydroxycholecalciferol. The remaining very small amount $(6 \%)$ of the radioactivity was mainly smeared throughout the area from the origin to the 25-hydroxycholecalciferol band. On silicic acid column chromatography of an extract of this pool of whole plasma, $13 \%$ of the ${ }^{3} \mathrm{H}$ was eluted in the cholecalciferol-containing fractions (fractions $3+4+5$ ) and $81 \%$ in fraction 8 .

TMS ether derivatives were formed with the extracts of two samples obtained on the 36th day of the study, which contained $89 \%$ of their ${ }^{8} \mathrm{H}$ content as the polar metabolite (eluted in column fraction 8) (see Methods). On subsequent TLC, most of the ${ }^{3} \mathrm{H}$ cochromatographed with the simultaneously formed TMS ether derivative of authentic carrier 25-hydroxycholecalciferol. After TLC in benezene-ethyl acetate $(3: 1) 81$ and $85 \%$ (for the two samples) of the recovered ${ }^{3} \mathrm{H}$ cochromatographed with the TMS carrier band $(R, 0.88)$; the remaining radioactivity was spread in a broad trailing zone behind this band. After two-dimensional TLC, 58\% and $73 \%$ of the recovered ${ }^{3} \mathrm{H}$ (for the two samples) cochromatographed with the TMS carrier spot. Since the recovery of the TMS derivative of 25-hydroxycholecalciferol after its formation and TLC was not expected to be quantitative, these data support the conclusion that the labeled metabolite in column fraction 8 had properties virtually identical with those of 25-hydroxycholecalciferol.

By saponification it was confirmed that the polar metabolite was not an ester or other saponifiable derivative of vitamin $D_{3}$. A sample of plasma proteins of $d>$ 1.21 was obtained from subject C. H. 56 days after injection of cholecalciferol- ${ }^{3} \mathrm{H}$. After extraction and silicic acid column chromatography, $96 \%$ of the ${ }^{3} \mathrm{H}$ in this sample was recovered in the 25-hydroxycholcalciferolcontaining fraction. After saponification of a portion of this extract, $98 \%$ of the ${ }^{8} \mathrm{H}$ was recovered with the nonsaponifiable lipids. The labeled nonsaponifiable lipid was eluted from a silicic acid column in a pattern identical with that seen for the labeled lipid in the extract before saponification (96\% of the ${ }^{3} \mathrm{H}$ recovered in the 25-hydroxycholecalciferol-containing fraction).

Ultracentrifugation at density 1.21. Plasma samples were separated into lipoproteins $(\mathrm{d}<1.21)$ and proteins of density greater than 1.21 at several times during the study. The distribution of radioactivity between these two fractions, for the subjects who were given $6 \mu \mathrm{g}$ of 'cholecalciferol- ${ }^{8} \mathrm{H}$, is shown in Table III. Almost all ( $>90 \%$, mean $94 \%$ ) of the ${ }^{8} \mathrm{H}$ was consistently found
TABLE III

Distribution of Radioactive Vitamin $D$ after Ultracentrifugation at Density 1.21*

\begin{tabular}{cc}
\hline Fraction & $\begin{array}{c}\text { Distribution } \\
\text { of } \\
\text { radioactivity } \ddagger\end{array}$ \\
\hline Lipoproteins $(\mathrm{d}<1.21)$ & $\%$ \\
Proteins with $\mathrm{d}>1.21$ & $6.1 \pm 0.8$ \\
\hline
\end{tabular}

* 14 samples were analyzed, which were collected from subjects A. B., F. B., R. H., and T. L. 2, 4, and 7 days after the injection of label, and from subjects R. H. and T. L. after 36 days.

$\ddagger$ Mean \pm SEM.

to be associated with the proteins of density greater than 1.21 . In these four subjects, slightly more radioactivity (mean of $8 \%$ of total ${ }^{3} \mathrm{H}$ ) was found in the lipoprotein fractions $(\mathrm{d}<1.21)$ at 2 days after isotope injection than at later intervals. On column chromatography of extracts of the 2-day samples, relatively more of the ${ }^{3} \mathrm{H}$ in the lipoprotein fractions than in the $\mathrm{d}>1.21$ fractions was found as esterified and as unchanged vitamin $D_{3}$. Similarly, with the subject who received the $80 \mu \mathrm{g}$ dose, 90,97 , and $98 \%$ of the plasma total ${ }^{3} \mathrm{H}$ was found associated with the proteins of density greater than 1.21 after 5,19 , and 56 days, respectively. In this subject, during the interval $12 \mathrm{hr}-3$ days (four samples) $81-87 \%$ of the ${ }^{8} \mathrm{H}$ was found in the $\mathrm{d}<1.21$ fraction. The results with the earliest samples collected suggest that a very small portion of the injected labeled vitamin $\mathrm{D}_{3}$ was circulating in association with the plasma lipoproteins during the early time intervals. Most of the vitamin $\mathrm{D}_{3}$, however, and virtually all of the polar metabolite with the properties of 25-hydroxycholecalciferol circulated in association with the proteins of density greater than 1.21 and not with the known plasma lipoproteins. This conclusion was confirmed by bioassay (see below).

Gel filtration. Gel filtration on Sephadex G-200 was performed with three plasma samples, each containing almost all of its radioactivity as the polar metabolite (see Methods for more details). These experiments provide information about the apparent molecular size of the transport protein for the polar metabolite. The results of a representative experiment are shown in Fig. 2. An identical elution pattern was obtained in each of five chromatographic runs. In each instance, almost all of the radioactivity was eluted in a peak with an elution volume very close to that of plasma albumin. The center of the peak of radioactvity was consistently found to be eluted very slightly after the center of the plasma albumin peak (see Fig. 2). These results suggest that the polar metabolite

Vitamin D Turnover and Transport in Man

2163 


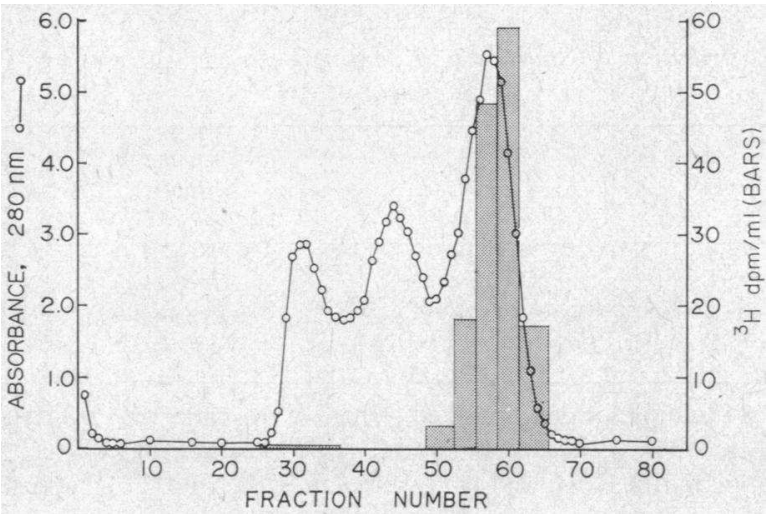

FIGURE 2 Gel filtration of whole plasma containing radioactive vitamin $\mathrm{D}$ metabolites. $6 \mathrm{ml}$ of whole plasma from a sample of pooled plasma collected from four subjects on day 7 (see Methods) was dialyzed successively three times, each time against 4 liters of $0.02 \mathrm{M} \mathrm{Na}$ phosphate buffer, $\mathrm{pH} 7.3$, containing $0.2 \mathrm{M} \mathrm{NaCl}$. The dialyzed sample was applied to a $2.5 \times 63 \mathrm{~cm}$ column (bed volume, $309 \mathrm{ml}$ ) of Sephadex G-200. The elution was conducted with the same buffer at a flow rate of $15 \mathrm{ml} / \mathrm{hr}$. Fractions of $3 \mathrm{ml}$ each were collected.

of vitamin $D_{\boldsymbol{z}}$ circulates in association with a protein of apparent molecular size very close to, but slightly smaller than, that of human plasma albumin.

Preparative polyacrylamide gel electrophoresis. The fractions comprising the ${ }^{3} \mathrm{H}$-containing peak after gel filtration were combined, and the protein was then subjected to preparative polyacrylamide gel electrophoresis.

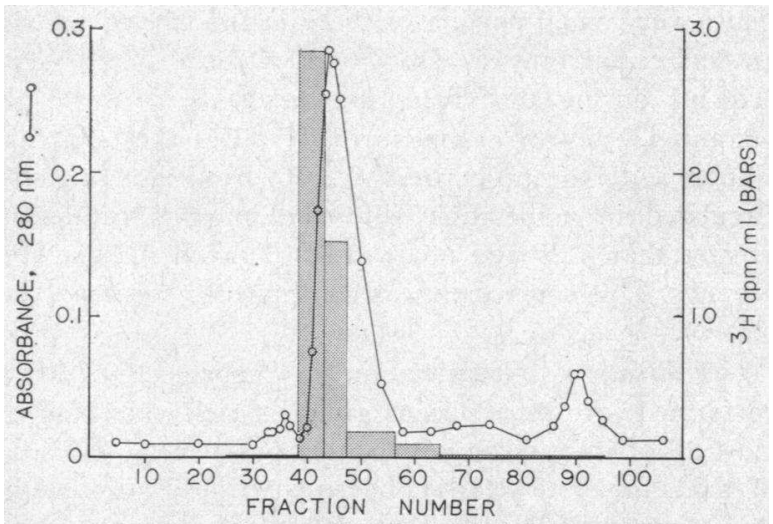

FIGURE 3 Preparative polyacrylamide gel electrophoresis. The fractions comprising the ${ }^{8} \mathrm{H}$-containing peak after gel filtration (e.g. fractions $50-66$ in Fig. 2) of the pooled sample from subject $\mathrm{C}$. $\mathrm{H}$. were concentrated by ultrafiltration (Diaflo UM-2 membrane; Amicon Corp., Lexington, Mass.) and dialyzed against water. $8 \mathrm{ml}$ of the concentrated sample containing $10 \mathrm{mg}$ of protein per $\mathrm{ml}$ in $5 \%$ sucrose was applied to a $9.5 \mathrm{~cm}$ high column of $7 \%$ acrylamide gel. The electrophoresis was conducted at a constant voltage of $400 \mathrm{v}$ and approximately $20 \mathrm{ma}$, with an elution rate of $40 \mathrm{ml} / \mathrm{hr}$. Fractions of $6 \mathrm{ml}$ were collected.
TABLE IV

Distribution of Vitamin D Activity in

Plasma by Bioassay

\begin{tabular}{lc}
\hline \multicolumn{1}{c}{ Sample assayed* } & $\begin{array}{c}\text { Distribution of total } \\
\text { bioassayable activity }\end{array}$ \\
\hline & $\%$ \\
Whole plasma & 100 \\
Lipoproteins $(\mathrm{d}<1.21)$ & 0 \\
Proteins with $\mathrm{d}>1.21$ & 100 \\
Fractions 3 $+4+5 \ddagger$ & 44 \\
Fraction $8 \ddagger$ & 55
\end{tabular}

* The samples assayed were derived from a sample of pooled plasma collected from subjects A. B., F. B., and R. H. on the 50th day of the study. The pooled plasma was estimated to contain a total vitamin D activity equivalent to $18 \mathrm{ng}$ of cholecalciferol per $\mathrm{ml}$.

$\ddagger$ After silicic acid column chromatography of an extract of whole plasma.

As shown in Fig. 3, the radioactivity migrated in a single sharp peak with a mobility very slightly greater than that of plasma albumin. In each of three experiments, the peak of radioactivity was found to be mainly located along the leading edge of the albumin peak. The mobility of the ${ }^{3} \mathrm{H}$-containing peak was distinctly less than that of plasma prealbumin, but considerably more than that of proteins with $\alpha$-mobility. The fractions containing the proteins with $\alpha_{1}$-mobility, identified by the fluorescence of retinol-binding protein (24), contained only $4 \%$ of the total radioactivity.

Bioassay. The results of a bioassay study are presented in Table IV. In this experiment, virtually all of the biological activity of whole plasma was recovered after ultracentrifugation at density 1.21 , in association with the sedimenting proteins of density greater than 1.21. Slightly more than half of the biological activity of plasma was found in fraction 8 after silicic acid column chromatography of an extract of plasma; the remainder was found in the cholecalciferol-containing fractions (fractions $3+4+5$ ).

These observations were confirmed in a later experiment using plasma collected from a normal $34 \mathrm{yr}$ old male subject who had not been injected with labeled cholecalciferol. In this subject, the vitamin $\mathrm{D}$ activity of an extract of whole plasma was equivalent to $26 \mathrm{ng}$ of cholecalciferol per ml of plasma. After ultracentrifugation, an extract of the proteins with $d>1.21$ contained bioactivity equivalent to $21 \mathrm{ng}$ of cholecalciferol per $\mathrm{mI}$ of plasma. The compounds recovered in fractions $3+$ $4+5$ and in fraction 8 , after silicic acid column chromatography, had bioactivity equivalent to 9 and $11 \mathrm{ng}$ of cholecalciferol per $\mathrm{ml}$ of plasma, respectively. 


\section{DISCUSSION}

The studies reported here demonstrate that the labeled polar metabolite which appears in plasma after the injection of radioactive vitamin $D_{3}$ has a relatively slow turnover with a half-life of $19.6 \pm 0.6$ days. In these studies, four of the five subjects were injected with a small, physiological dose $(6 \mu \mathrm{g})$ of vitamin $D_{s}$, which was well within the recommended daily allowance of vitamin D (14). After injection the labeled vitamin $D_{3}$ disappeared rapidly from plasma, with an initial halflife of approximately $12 \mathrm{hr}$. After 7 days, labeled unchanged vitamin $D_{3}$ represented less than $1 \%$ of the circulating radioactivity. Coincident with the disappearance of labeled vitamin $\mathrm{D}_{3}$ a more polar component appeared, with chromatographic and other properties of 25-hydroxycholecalciferol. Most (approximately $92 \%$ ) of the plasma total radioactivity was represented by this component throughout the later part of the study.

The properties of the labeled polar metabolite were compared directly with those of authentic 25-hydroxycholecalciferol. The labeled metabolite cochromatographed with 25-hydroxycholecalciferal on silicic acid columns and on thin layers of silica gel. The two components also cochromatographed during TLC in two different systems after formation of the TMS ether derivatives. Finally, the labeled polar metabolite was shown to be a nonsaponifiable lipid whose chromatographic properties were not altered by saponification. These findings indicate that the labeled polar metabolite in plasma was either 25-hydroxycholecalciferol itself or an extremely similar compound with properties identical with those of 25-hydroxycholecalciferol in the systems examined (or a mixture of such nearly identical compounds). In view of the demonstrated biological activity of the fraction containing the polar metabolite, it is reasonable to conclude that the labeled polar metabolite was probably 25-hydroxycholecalciferol.

A slow disappearance of plasma total radioactivity, after the injection of labeled vitamin $\mathrm{D}_{\mathbf{3}}$ into human subjects, has been reported by Mawer et al. (13). In contrast with our findings, however, Mawer et al. reported that after the initial rapid disappearance of labeled vitamin $D_{3}$ from plasma and the appearance of labeled polar metabolites, both the unchanged vitamin $\mathrm{D}_{3}$ and its polar metabolites exhibited a prolonged phase with a slow turnover rate. The half-life of labeled vitamin $\mathrm{D}_{3}$ during this later phase of slow turnover was 18-36 days, while that of plasma total radioactivity was $20-44$ days (13). The differences between these observations and our own may possibly be explained by the relatively large doses of labeled vitamin $\mathrm{D}_{3}(110$ and $216 \mu \mathrm{g})$ injected by Mawer et al. Consistent with this explanation is our finding that the disappearance rate of labeled vitamin $D_{s}$ in the subject who received an $80 \mu \mathrm{g}$ dose was consider- ably slower and more prolonged than that seen in the subjects who were given $6 \mu \mathrm{g}$. This explanation is also supported by the results of Schaefer, Koch, Opitz, von Herrath, and Knoop (29) who injected small doses of labeled vitamin $D_{s}(12.5 \mu \mathrm{g})$ into normal humans and patients with renal disease and found that unchanged vitamin $D_{3}$ represented only approximately $2 \%$ of the plasma- ${ }^{8} \mathrm{H}$ after 7 days. Moreover, more recently Mawer, Lumb, Schaefer, and Stanbury have reported that the disappearance rate of radioactive vitamin $\mathrm{D}_{3}$ was slower in subjects receiving large doses of vitamin $D$ than in patients relatively deficient in vitamin $D(30)$.

By combining the results of the bioassay experiments with those of the turnover studies, an estimate can be obtained of the steady-state turnover of plasma 25-hydroxycholecalciferol in man. The bioassay studies suggested that the plasma samples contained 8-9 ng of cholecalciferol per $\mathrm{ml}$ and an amount of 25-hydroxycholecalciferol with bioactivity equivalent to $10-11 \mathrm{ng}$ of cholecalciferol per $\mathrm{ml}$. The biological activity of 25-hydroxycholecalciferol has been reported to be 1.4 times (3) and 1.78 times (8) that of cholecalciferol, on a per unit mass basis. By using a mean of these values, we can conclude that the samples bioassayed contained approximately $7 \mathrm{ng}$ of 25 -hydroxycholecalciferol per $\mathrm{ml}$. If we now estimate the plasma volume as $\mathbf{3}$ liters and the extravascular (and extracellular) compartment as being similar to that for serum albumin (1.4 times the intravascular compartment [31]), we can estimate the sizes of the intravascular and extravascular pools of 25-hydroxycholcalciferol. These calculations indicate that the plasma compartment contained a total of approximately $21 \mathrm{\mu g}$, and the extravascular compartment a total of approximately $29 \mu \mathrm{g}$, giving a total extracellular pool of approximately $50 \mu \mathrm{g}$ of 25 -hydroxycholecalciferol. Given a half-life of 19.6 days and assuming a fully miscible extracellular compartment which behaved as a single pool during the later phase of the turnover study, these data suggest that the steady-state turnover of 25-hydroxycholecalciferol in the extracellular compartment was approximately $1.3 \mu \mathrm{g}$ per day. This is equivalent to a steadystate turnover of 80-85 IU of biological activity per day. A comparable estimate cannot be made for vitamin $D_{3}$ itself because of the likelihood that the disappearance rate observed during the first days of study represented an unsteady state with regard to the turnover and metabolism of the labeled material.

The experiments reported here conclusively demonstrate that significant amounts of neither vitamin D nor its polar metabolite (presumably 25-hydroxycholecalciferol) circulate in plasma in association with any of the known plasma lipoproteins. In each of the several time intervals studied, almost all (mean 94\%) of the plasma radioactivity was found associated with the 
proteins of density greater than 1.21 . A very small portion of the injected labeled vitamin $D_{3}$ was found in association with the plasma lipoproteins during the shortest time intervals studied. The bioassay experiments demonstrated that biological activity associated with both vitamin $\mathrm{D}_{3}$ and with the 25-hydroxycholecalciferolcontaining fraction, was found in association with the plasma proteins of density greater than 1.21. In contrast, cholesterol and other lipids (except for FFA [32] and lysolecithin [33]) circulate in plasma mainly as part of plasma lipoprotein molecules with hydrated densities of less than $1.21(23,34)$. Since both cholecalciferol and its 25-hydroxy derivative are sterol derivatives and nonsaponifiable lipid alcohols, the fact that these molecules circulate in association with proteins of density greater than 1.21 provides presumptive evidence for the existence of a specific transport protein (or proteins) for these compounds.

This conclusion is supported by recent studies in our laboratory dealing with the transport of retinol (vitamin A alcohol) in plasma. Beginning with the observation that retinol circulates in plasma in association with proteins of density greater than 1.21 , we were able to develop a fractionation sequence for the isolation of retinol-binding protein ( $R B P)$, the specific transport protein for plasma vitamin A (24). RBP has now been characterized to a considerable extent $(24,35,36)$.

The plasma protein responsible for the transport of 25-hydroxycholecalciferol has been partly characterized with regard to apparent molecular size and to electrophoretic mobility. Since the plasma samples which were examined in these experiments contained almost all their radioactivity as the polar (25-hydroxy) metabolite, comparable information is not available about the transport protein for vitamin $\mathrm{D}_{\mathbf{3}}$ itself. It remains for future studies to determine whether the same or different proteins are responsible for the transport of vitamin $D$ and of 25-hydroxycholecalciferol. Gel filtration on Sephadex G-200 indicated that the polar metabolite (presumed to be 25-hydroxycholecalciferol) circulates in association with a protein of apparent molecular size very close to, but slightly smaller than, that of human plasma albumin. The mol wt of the protein can be estimated as approximately 50,000-60,000. On polyacrylamide gel electrophoresis the transport protein displayed mobility very slightly greater than that of plasma albumin. If we assume that the protein contains one binding site for one molecule of 25-hydroxycholecalciferol and that the protein circulates almost entirely as the holo-protein containing a molecule of bound 25-hydroxycholecalciferol, then the concentration of the transport protein would be of the order of $1 \mathrm{mg} /$ liter of plasma. These assumptions are based upon our experience with plasma RBP (24, 36). Should plasma vitamin $D_{3}$ be transported by the same protein, then the level of the protein in plasma would be of the order of 2-3 mg/liter. Studies are in progress in our laboratory in an attempt to further fractionate and characterize the transport protein.

\section{ACKNOWLEDGMENTS}

We are grateful to Dr. D. Schachter and Mr. S. Kowarski for instruction in the vitamin D bioassay method. We thank Doctors P. Milch and Y. Muto for constructive criticism and assistance with the bioassay. Mrs. M. Bloom provided technical assistance. We thank Dr. J. C. Babcock of the Upjohn Co. for the gift of 25-hydroxycholecalciferol.

This work was supported by grant AM-05968 from the National Institutes of Health.

\section{REFERENCES}

1. Avioli, L. V., S. W. Lee, J. E. McDonald, J. Lund, and H. F. DeLuca. 1967. Metabolism of vitamin $\mathrm{D}_{{ }_{3}}{ }^{3} \mathrm{H}$ in human subjects: distribution in blood, bile, feces, and urine. J. Clin. Invest. 46: 983.

2. Ponchon, G., A. L. Kennan, and H. F. DeLuca. 1969. "Activation" of vitamin D by the liver. J. Clin. Invest. 48: 2032.

3. Blunt, J. W., H. F. DeLuca, and H. K. Schnoes. 1968. 25-Hydroxycholecalciferol. A biologically active metabolite of vitamin $\mathrm{D}_{3}$. Biochemistry. $7: 3317$.

4. DeLuca, H. F. 1969. Recent advances in the metabolism and function of vitamin D. Fed. Proc. 28: 1678.

5. Olson, E. B., and H. F. DeLuca. 1969. 25-Hydroxycholecalciferol: direct effect on calcium transport. Science (Washington). 165: 405.

6. Trummel, C. L., L. G. Raisz, J. W. Blunt, and H. F. DeLuca. 1969. 25-Hydroxycholecalciferol: stimulation of bone resorption in tissue culture. Science (Washington). 163: 1450 .

7. Cousins, R. J., H. F. DeLuca, and R. W. Gray. 1970. Metabolism of 25-hydroxycholecalciferol in target and nontarget tissues. Biochemistry. 9: 3649.

8. Myrtle, J. F., and A. W. Norman. 1971. Vitamin D: a cholecalciferol metabolite highly active in promoting intestinal calcium transport. Science (Washington). 171: 79.

9. Haussler, M. R., D. W. Boyce, E. T. Littledike, and H. Rasmussen. 1971. A rapidly acting metabolite of vitamin D. Proc. Nat. Acad. Sci. U. S. A. 68: 177.

10. Fraser, D. R., and E. Kodicek. 1970. Unique biosynthesis by kidney of a biologically active vitamin $D$ metabolite. Nature (London). 228: 764.

11. DeLuca, H. F. 1971. Editorial: role of kidney tissue in metabolism of vitamin D. N. Engl. J. Med. 284: 554.

12. Avioli, L. V., T. F. Williams, J. Lund, and H. F. DeLuca. 1967. Metabolism of vitamin $\mathrm{D}_{3^{-}}{ }^{3} \mathrm{H}$ in vitamin Dresistant rickets and familial hypophosphatemia. J. Clin. Invest. 46: 1907.

13. Mawer, E. B., G. A. Lumb, and S. W. Stanbury. 1969. Long biological half-life of vitamin $\mathrm{D}_{3}$ and its polar metabolites in human serum. Nature (London). 222: 482.

14. National Research Council, Report of the Food and Nutrition Board. 1968. Recommended dietary allowances. National Academy of Sciences-National Research Council, Washington. 7th edition. 24.

15. Thomas, W. C., Jr., H. G. Morgan, T. B. Connor, L. Haddock, C. E. Bills, and J. E. Howard. 1959. Stud- 
ies of antiricketic activity in sera from patients with disorders of calcium metabolism and preliminary observations on the mode of transport of vitamin $D$ in human serum. J. Clin. Invest. 38: 1078.

16. de Crousaz, P., B. Blanc, and I. Antener. 1965. Vitamin $\mathrm{D}$ activity in normal human serum and serum proteins. Helv. Odontol. Acta. 9: 151.

17. Chen, P. S., Jr., and K. Lane. 1965. Serum protein binding of vitamin $\mathrm{D}_{3}$. Arch. Biochem. Biophys. 112: 70.

18. Chalk, K. J. I., and E. Kodicek. 1961. The association of ${ }^{14} \mathrm{C}$-labelled vitamin $\mathrm{D}_{2}$ with rat serum proteins. Biochem. J. 79: 1.

19. Rikkers, H., and H. F. DeLuca. 1967. An in vivo study of the carrier proteins of ${ }^{8} \mathrm{H}$-vitamin $\mathrm{D}_{3}$ and $\mathrm{D}_{4}$ in rat serum. Amer. J. Physiol. 213: 380.

20. Goodman, DeW. S., and T. Shiratori. 1964. Fatty acid composition of human plasma lipoprotein fractions. $J$. Lipid Res. 5 : 307.

21. Whyte, M., A. Karmen, and DeW. S. Goodman. 1963. Fatty acid esterification and chylomicron formation during fat absorption: 2: Phospholipids. J. Lipid Res. 4: 322.

22. Grundy, S. M., E. H. Ahrens, Jr., and T. A. Miettinen. 1965. Quantitative isolation and gas-liquid chromatographic analysis of total fecal bile acids. J. Lipid Res. $6: 397$.

23. Havel, R. J., H. A. Eder, and J. H. Bragdon. 1955. The distribution and chemical composition of ultracentrifugally separated lipoproteins in human serum. J. Clin. Invest. $34: 1345$.

24. Kanai, M., A. Raz, and DeW. S. Goodman. 1968. Retinol-binding protein: the transport protein for vitamin $A$ in human plasma. J. Clin. Invest. 47: 2025.

25. Schachter, D., D. V. Kimberg, and H. Schenker. 1961. Active transport of calcium by intestine: action and bioassay of vitamin D. Amer. J. Physiol. 200: 1263.
26. Gordan, G. S., and D. Schachter. 1963. Vitamin D activity of normal and neoplastic human breast tissue. Proc. Soc. Exp. Biol. Med. 113: 760.

27. Bray, G. A. 1960. A simple efficient liquid scintillator for counting aqueous solutions in a liquid scintillation counter. Anal. Biochem. 1: 279.

28. Snedecor, G. W., and W. G. Cochran. 1967. Statistical Methods. 6th edition. Iowa State University Press, Ames, Iowa. 50 and 135.

29. Schaefer, K., H. U. Koch, A. Opitz, D. von Herrath, and H. Knoop. 1970. Vitamin D-Stoffwechsel und Niereninsuffizienz. Klin. Wochenscher. 48: 1129.

30. Mawer, E. B., G. A. Lumb, K. Schaefer, and S. W. Stanbury. 1971. The metabolism of isotopically labelled vitamin $\mathrm{D}$, in man: the influence of the state of vitamin D nutrition. Clin. Sci. (London). 40: 39.

31. Beeken, W. L., W. Volwiler, P. D. Goldsworthy, L. E. Garby, W. E. Reynolds, R. Stogsdill, and R. S. Stemler. 1962. Studies of $\mathrm{I}^{131}$-albumin catabolism and distribution in normal young male adults. J. Clin. Invest. 41: 1312.

32. Fredrickson, D. S., and R. S. Gordon, Jr. 1958. Transport of fatty acids. Physiol. Rev. 38: 585.

33. Switzer, S., and H. A. Eder. 1965. Transport of lysolecithin by albumin in human and rat plasma. J. Lipid Res. 6: 506.

34. Fredrickson, D. S., R. I. Levy, and R. S. Lees. 1967. Fat transport in lipoproteins-an integrated approach to mechanisms and disorders. N.. Engl. J. Med. 276: 34.

35. Raz, A., T. Shiratori, and DeW. S. Goodman. 1970. Studies of the protein-protein and protein-ligand interactions involved in retinol transport in plasma. J. Biol. Chem. 245: 1903.

36. Smith, F. R., A. Raz, and DeW. S. Goodman. 1970. Radioimmunoassay of human plasma retinol-binding protein. J. Clin. Invest. 49: 1754. 